\title{
The skill of administering IM medications: 3 questions to consider
}

Raj K. Kalapatapu, MD, PhD, and Gregory A. Ramos, MSN, RN

Dr. Kalapatapu is Associate Professor, Psychiatry, University of California San Francisco School of Medicine, and Attending Psychiatrist, Psychiatric Emergency Services, Zuckerberg San Francisco General Hospital and Trauma Center, San Francisco, California. Mr. Ramos is a Psychiatric Nurse, Psychiatric Emergency Services, Zuckerberg San Francisco General Hospital and Trauma Center, San Francisco, California.

\section{Disclosures}

The authors report no financial relationships with any companies whose products are mentioned in this article, or with manufacturers of competing products.

doi: $10.12788 /$ cp.0219

\section{$f$}

Discuss this article at www.facebook.com/ MDedgePsychiatry 6
$\mathrm{T}$ he intramuscular (IM) route is commonly used to administer medication in various clinical settings. Even when an IM medication is administered appropriately, patient factors such as high subcutaneous tissue, greater body mass index, and gender can lower the success rate of injections. ${ }^{1}$ A key but infrequently discussed issue is the skill of the individual administering the IM medication. Incorrectly administering an IM medication can lead to complications, such as abscesses, nerve injury, and skeletal muscle fibrosis. ${ }^{2}$ Poor IM injection technique can impact patient care and safety. ${ }^{1}$ For example, a poorly administered antipsychotic medication might lead to the patient receiving a subtherapeutic dose, and could prompt a clinician to ask, "Does this agitated patient need more emergent medication because the medication being given is not effective, or because the medication is not being administered properly?"

This article offers 3 questions to ask when clinicians are evaluating how IM medications are being administered in their clinical setting.

Who is administering the medication? Is the person a registered nurse, licensed psychiatric technician, certified nursing assistant, licensed vocational nurse, or medical assistant? What a specific clinician is permitted to do in one state may not be permitted in another state. For example, in the state of Washington, under certain conditions a medical assistant is allowed to administer an IM medication. ${ }^{3}$
What is the individual's training in administering IM medications? Has the person been trained in the proper technique, depending on the body location? Is the injection being properly prepared? Is the correct needle gauge being used?

What is the individual's comfort level with administering IM medications? Is the person comfortable administering medication only when a patient is calm? Or are they comfortable administering medication when a patient is agitated and being physically held or in 4-point restraints, such as in inpatient psychiatric units or emergency departments?

\section{References}

1. Soliman E, Ranjan S, Xu T, et al. A narrative review of the success of intramuscular gluteal injections and its impact in psychiatry. Biodes Manuf. 2018;1(3):161-170.

2. Nicoll LH, Hesby A. Intramuscular injection: an integrative research review and guideline for evidence-based practice. Appl Nurs Res. 2002;15(3):149-162.

3. Washington State Legislature. WAC 246-827-0240. Medical assistant-certified-Administering medications and injections. Accessed January 10, 2022. https://apps. leg.wa.gov $/$ wac $/$ default.aspx?cite $=246-827-0240$

Every issue of CURRent Psychiatry has its 'Pearls'

Yours could be found here.

Read the 'Pearls' guidelines for manuscript submission at MDedge.com/ CurrentPsychiatry/page/pearls. Then, share with your peers a 'Pearl' of wisdom from your practice. 